probable that the bond distribution of quadricovalent metals is determined by their principal valency. We have now examined some derivatives of bivalent tin and lead, and find, in agreement with this view, that they are planar. It is well known that quadrivalent tin and lead, like carbon, silicon and germanium, show a tetrahedral disposition of valencies; quadrivalent tin is of particular interest, since it furnished one of the first examples ${ }^{2}$ of optical activity due to an asymmetric atom other than carbon.

The bivalent tin compounds examined by X-ray methods include the isomorphous double halides $\mathrm{R}_{2}\left[\operatorname{SnX} X_{4}\right] 2 \mathrm{H}_{2} \mathrm{O}\left(\mathrm{R}=\mathrm{K}\right.$ or $\mathrm{NH}_{4}, \mathrm{X}=\mathrm{Cl}$ or $\left.\mathrm{Br}\right)$. The unit cell of potassium chlorostannite has dimensions $a=12 \cdot 02, b=9 \cdot 11, c=8 \cdot 23 \mathrm{~A}$., and contains four molecules. The symmetry of its space group, Pnma, requires the ion $\left[\mathrm{SnCl}_{4}\right]^{--}$to have either a plane or a centre of symmetry, but the former appears to be excluded by the intensities of the $\mathrm{X}$-ray reflections, and the four valencies of the central tin atom are therefore centro-symmetrical, that is, coplanar. The results exclude the possibility of a hexacovalent complex $\left[\mathrm{SnCl}_{4} 2 \mathrm{H}_{2} \mathrm{O}\right]^{-}-$.

With Mr. K. C. Webster we have also studied the following compounds of bivalent lead: potassium plumbo-oxalate, di-thiourea lead chloride, lead salicylate and lead bis-benzoylacetone. In the case of the first three, the smallest cell dimensions $(4 \cdot 03$, 3.99 and $4.85 \mathrm{~A}$., respectively) alone exclude the possibility of tetrahedral structures. Di-thiourea lead chloride, $\mathrm{PbCl}_{2} .2 \mathrm{CS}\left(\mathrm{NH}_{2}\right)_{2}$, has cell dimensions $a=20 \cdot 67, b=3.99$ and $c=11.98 \mathrm{~A}$., and space group Pna. In addition to the space group halvings, all planes with $h$ odd give exceedingly weak reflections, and the molecule therefore very nearly has a plane of symmetry parallel to $(010)$. This is only possible if it is nearly or quite flat. Lead bisbenzoylacetone has cell dimensions $a=23 \cdot 41$, $b=7.77$ and $c=9.96 \mathrm{~A}$., the space group being Pcn. Here also additional pseudo-halvings oceur, showing that the molecule very nearly has $C_{2 v}$ symmetry, which is only possible if it has a planar configuration.

The detailed results of the analysis of these compounds will be published elsewhere.

E. G. Cox.

A. J. Shorter.

W. WARDLAW.

Chemistry Department,

University,

Birmingham.

Dee. 16.

' Cox, Wardlaw and Webster, J. Chem. Soc., 775 (1936); Mann, Purdie and Wells, J. Chem. Soc., 1503 (1936).

${ }^{2}$ Pope and Peachey, Proc. Chem. Soc., 42, 116 (1900).

\section{Realgar in Wookey Hole, Somerset}

Some two years ago, when examining relics from Wookey Hole, kept in the Wells Museum, I noticed a vessel containing a small amount of a ruby-coloured powder, elosely resembling realgar or ruby sulphur. Mr. H. E. Balch, the curator and well-known authority on Wookey Hole, informed me that the powder was found in the Roman stratum of the cave floor. $\mathrm{He}$ courteously gave no a small sample which $I$ later submitted to chemical tests and confirmed my first impression.
Realgar is found widely distributed in many parts of Europe, but so far as I am aware, it has never been found in Britain. How, then, did the specimen come to be in Wookey Hole? Mr. Balch, in answer to my query, stated that no mural paintings had been discovered so far in the Mendip caves, which rendered it improbable, though not impossible, that the realgar had been imported for mural decorative purposes.

Since then my attention has been directed to the belief that realgar was used medicinally by the

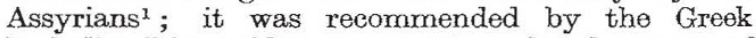
herbalist Dioscorides, c. A.D. 50, under the name of sandarach, for inhaling when burned with resin; finally Pliny" in his "Natural History" refers to its use for a variety of medical purposes. Thus he says: "Taken with the food, in combination with turpentine, it is a pleasant [sic] cure for cough and asthma. In the form of a fumigation also, with cedar, it has a. remedial effect upon those complaints."

As Wookey Hole is very damp, we can visualize its inhabitants suffering from bronchial affections; it seems reasonable to suppose that the realgar had been imported for medical use.

\section{Technical College, Birmingham.} Nov. 27.

"See Partington, "Origins and Development of Applied Chemistry", p. 317 (1935).

2 Bostock and Riley's Translation, Book 34, chapter 17.

\section{The Hexlet}

Crrcles which touch cyclically may be called a ring. Two rings will touch when each member of the one touches each member of the other; and so for spheres.

Prof. Soddy has given in verse ${ }^{I}$ the notable theorem that, given a three-ring of spheres, and beginning with any sphere touching it, the sphere belongs to a six-ring touching it.

A proof is as follows.

A penny on a plane can be touched by a ring of six pennies, poristically (that is, beginning where we please). Thus a unit sphere on a plane can be touched by a ring of six unit spheres. On the seven can be laid a second plane, parallel to the first plane. Under inversions, parallel planes are touching spheres. Thus we have the Soddy configuration of a three-ring touched by a six-ring, in its initial form.

When we discuss contacts of spheres, the spheres are directed. A normal, and thereby all normals, carry an arrow-head. The contact of two directed spheres is positive when the arrow-heads agree, otherwise negative. For a ring of three spheres the contacts can not be all positive. We take them all negative. Thus contact here means negative contact. In the initial case, the seven unit spheres have all negative contact. We have a ring of three spheres with bends $b_{1}, b_{2}, b_{3}$ touched by a ring of six spheres with bends $b_{4}, b_{5}, \ldots b_{9}$.

Prof. Soddy's formula is

$$
b_{4}+b_{7}=2\left(b_{1}+b_{2}+b_{3}\right) \text {. }
$$

Initially, $b_{4}=b_{7}=1, b_{1}=1, b_{2}=b_{3}=0$. Thus the formula is true initially. 